\title{
Evaluation of synthesized polyaniline nanofibres as corrosion protection film coating on copper substrate by electrophoretic deposition
}

\author{
Mohammed Fuseini ${ }^{1,2}$, Moustafa Mahmoud Yousry Zaghloul ${ }^{3,4, *}$ (D), Marwa F. Elkady ${ }^{5}$, and \\ Ahmed H. El-Shazly ${ }^{1}$ \\ ${ }^{1}$ Chemical and Petrochemicals Engineering Department, Egypt-Japan University of Science and Technology (E-JUST), Alexandria, \\ Egypt \\ ${ }^{2}$ Materials and Metallurgical Engineering Department, Kwame Nkrumah University of Science and Technology (KNUST), Kumasi, \\ Ghana \\ ${ }^{3}$ School of Mechanical and Mining Engineering, The University of Queensland, Brisbane, Australia \\ ${ }^{4}$ Centre for Advanced Materials Processing and Manufacturing (AMPAM), The University of Queensland, Brisbane, Australia \\ ${ }^{5}$ Fabrication Technology Department, Advanced Technology and New Materials Institute (ATNMRI), City of Scientific Research and \\ Technology Applications (SRATA CITY), Alexandria, Egypt
}

Received: 20 September 2021 Accepted: 4 February 2022 Published online:

4 March 2022

(C) Crown 2022

\begin{abstract}
In this current paper, we report the use of inexpensive, simple electrophoretic deposition (EPD) technique in developing polyaniline (PANI) aqueous colloidal suspension coating on copper $(\mathrm{Cu})$ substrate. Polyaniline nanoparticle films were deposited electrophoretically on the surface of copper sheet electrode. A colloidal suspension with high stability was produced by a liquid polyaniline in the presence of formic acid and acetonitrile as electrolyte for the EPD process. The suspension of the PANI was characterized by measuring the zeta potential of the suspension using zeta-sizer analyser. The PANI coating was used as barrier for corrosion protection of the $\mathrm{Cu}$ sheet. Operating parameters such as operating time, applied voltage, and the concentration were used with deposition at the cathode. Characterization such as XRD, SEM, FT-IR, and UV-Vis was carried out, and the corrosion protection offered by the PANI on the Cu surface was examined using potentiodynamic (Tafel) polarization in $3.5 \% \mathrm{NaCl}$ solution at room temperature. As a result, the optimum parameters for obtaining a homogenous coating on the $\mathrm{Cu}$ sheet were attained at the voltage of $15 \mathrm{~V}$ and deposition time of $180 \mathrm{~s}$ with $50 \mathrm{mg} / \mathrm{mL}$ PANI concentration. The attained results indicated inhibition efficiency for PANI deposit of $92.92 \%$ indicating protection against corrosion.
\end{abstract}

Handling Editor: Chris Cornelius.

Address correspondence to E-mail: Eng_Moustafaa@hotmail.com 


$\begin{array}{ll}\text { Abbreviations } \\ \mathrm{C}_{2} \mathrm{H}_{3} \mathrm{~N} & \text { Acetonitrile } \\ \mathrm{APS} & \text { Ammonium persulphate } \\ \mathrm{BSD} & \text { Backscattered detector } \\ \mathrm{BSED} & \text { Backscattered electron detector } \\ \mathrm{Cl}^{-} & \text {Chlorine ions } \\ \mathrm{Cu} & \text { Copper } \\ \text { Icorr } & \text { Corrosion current density } \\ \text { Ecorr } & \text { Corrosion potential } \\ \mathrm{CR} & \text { Corrosion rate } \\ D & \text { Dislocation density } \\ g & \text { Distortion parameter } \\ \text { EPD } & \text { Electrophoretic deposition } \\ \mathrm{ES} & \text { Emeraldine salt } \\ \mathrm{HCOOH} & \text { Formic acid } \\ \mathrm{FT}-\mathrm{IR} & \text { Fourier transform infrared } \\ \mathrm{HR}-\mathrm{TEM} & \text { High-resolution transmission electron } \\ & \text { microscopy } \\ \mathrm{HCL} & \text { Hydrochloric acid } \\ R & \text { Interchain separation } \\ d & \text { Interplanar distance } \\ \varepsilon & \text { Micro-strain } \\ \text { mpy } & \text { Mils per year } \\ \mathrm{OCP} & \text { Open-circuit potential } \\ P \% & \text { Percentage porosity } \\ R_{\mathrm{p}} & \text { Polarization resistance } \\ \mathrm{PANI} & \text { Polyaniline } \\ \mathrm{SEM} & \text { Scanning electron microscopy } \\ \mathrm{UV}-\mathrm{Vis} & \text { Ultraviolet-Visible spectroscopy } \\ & \end{array}$

\section{Introduction}

Copper and its alloys have many properties that make them stand out, and such properties play vital role in it functions. Among such properties are: excellent in heat conduction, excellent conductivity electrically, easy to machine, resistance to bio-fouling, and resistance to corrosion. However, it cannot be exempted when it comes to corrosion. Corrosion of copper leads to a substantial economic loss which requires extensive attention in limiting its impact on the copper and the society at large $[1,2]$. It is therefore pertinent to device an economic viable route in mitigating the situation. Organic coatings which incorporate chromium or lead for coating metallic surfaces are strictly prohibited due to it detrimental effects on human health and the environment at large [3]. Development of intrinsic conducting polymers and polymeric composite materials in recent years has gained much attention due to their flexibility [4], ease in processing [5], high mechanical properties $[6,7]$, and electrical conductivity $[8,9]$. Among such conducting polymers, polyaniline (PANI) has attracted a considerable attention because of its ease in synthesis, electrical conductivity, economic viability, environmental stability, and excellent resistance to corrosion [10].

Various methods for depositing polyaniline colloidal suspension on a conductive substrate have been proposed, such as thermal decomposition and chemical vapour deposition [11, 12]. However, a lot of advantages could be derived from room temperature deposition over high temperature deposition method [13]. Inkjet printing and Langmuir are some of the methods that could be used to deposit polyaniline colloidal suspension on a substrate [14, 15]. These methods, however, become problematic in terms of assembling PANI layers due the high temperature; it requires and complexity of its instrumentation [16]. Deposition through colloidal suspension route is a room temperature and ambient process. Therefore, suspension in colloidal form is a deposition method which includes electrophoretic deposition technique. This technique could be used to easily deposit a uniform nano-sized materials on a solid conducting substrate which is cost-effective and can simply be used for variety of applications $[17,18]$. In regards to the potential technological application of the EPD as a technique for processing materials, it is recognized by technologists and scientists. Notwithstanding its conventional fabrication application of an anti-oxidant and wear resistant in coating of ceramics, functional films fabrication for an advanced micro-electronic device, and novel composites development or medical implants bioactive coatings as well as solid oxide fuel cells, research on its nanoscale assembly in the area of advanced functional materials is still ongoing.

The possibility of nanotechnology and nanoscience in the design of an environmentally friendly, strong oxidation and resistance to corrosion in increasing the life span of materials under harsh environmental condition becomes a very crucial requirement in several applications $[19,20]$. For instance, the high performance of anti-corrosion of nanocomposites 
coatings of benzoxazine monomer could be assigned to the modified nano-clay, leading to improved properties of the barrier as a result of decreasing coatings permeability for water and oxygen species [21]. The amide functional group incorporation into the coatings of polybenzoxazine was found to be the effective approach for obtaining high-performance corrosion protection [22]. The addition of $3.0 \mathrm{wt} \%$ nano-clay and $20 \mathrm{wt} \%$ epoxidized soybean oil reduced the rate of corrosion by an order of one magnitude $\left(2.653 \times 10^{-3} \mathrm{~mm}\right.$ year $\left.^{-1}\right)$ in comparison with the pure poly-cyclohexane functionalized polybenzexozine $\left(1.292 \times 10^{-2} \mathrm{~mm}\right.$ year $\left.{ }^{-1}\right)$ in an order of two magnitudes when compared to bare mild steel $\left(1.094 \times 10^{-1} \mathrm{~mm}\right.$ year $\left.{ }^{-1}\right)$ with a resistance efficiency of $98.16 \%$, which remarkably reveals increment in the properties of the barrier of the composite coatings about the corrosive species [23].

The formation of colloidal dispersion of polyaniline has been used as leverage in bypassing the processing limitations due to the insoluble nature of it in common solvents [24]. The indistinguishability of a stable suspension appearance from a true solution makes it perfect approach. In a work reported previously, dispersion polymerization is the process used to produce colloidal suspension of PANI [25]. This method uses mixture of aqueous solution containing monomer (aniline) and suitable stabilizer in the presence of oxidants. As the monomer polymerized, the steric stabilizer surface layer attaches to the PANI particle precipitates, which protects the precipitates particle from accumulation. As a result, a stable dispersion of colloidal suspension particles of PANI may be achieved. The colloidal suspension prepared from the dispersion polymerization has a structural 'core shell'. The composition of the core is an insoluble PANI coated with the shell from stable colloidal ultrafine inorganic of the steric stabilizer or soluble water polymer. The setback in using dispersion polymerization to form a colloidal suspension is that the issue of processability is mitigated through compromising the purity of the PANI. Notwithstanding this, the insulating layer of the polymer on the interfacial and surface properties of the PANI may be detrimental [26].

In this study, we outline cost-effective technique for forming a colloidal suspension from polyaniline. An efficient method of depositing the colloidal suspension from polyaniline on copper substrate using electrophoretic deposition technique would be employed. The deposition shall be used to test its resistance to corrosion by means of potentiodynamic (Tafel) polarization. To the best of our knowledge, this simple method of colloidal suspension using polyaniline, formic acid, and acetonitrile on copper sheet for corrosion protection has not been reported. This if successful could bring the woes of industries that uses copper sheet in its line of work to an appreciable level.

\section{Methodological approach}

\section{Preparation of polyaniline}

Aniline $\left(\mathrm{C}_{6} \mathrm{H}_{5} \mathrm{NH}_{2}\right)$, ammonium persulphate (APS), hydrochloric acid $(\mathrm{HCl})$, formic acid $(\mathrm{HCOOH})$, acetonitrile $\left(\mathrm{C}_{2} \mathrm{H}_{3} \mathrm{~N}\right)$ of analytical grade were used as received; aniline was double distilled under vacuum pressure; deionized water was used throughout this work.

List of chemicals and base fluid used in the experimental study:

\begin{tabular}{|c|c|c|c|}
\hline Material & $\begin{array}{l}\text { Chemical } \\
\text { formula }\end{array}$ & Quantity & $\begin{array}{l}\text { Chemical/physical } \\
\text { properties }\end{array}$ \\
\hline Aniline & $\mathrm{C}_{6} \mathrm{H}_{5} \mathrm{NH}_{2}$ & $40 \mathrm{ml}$ & $\begin{array}{l}\text { used as an inhibitor } \\
\text { for metals }\end{array}$ \\
\hline $\begin{array}{l}\text { Ammonium } \\
\text { persulphate }\end{array}$ & {$\left[\left(\mathrm{NH}_{4}\right)_{2} \mathrm{~S}_{2} \mathrm{O}_{8}\right]$} & $24 \mathrm{~g}$ & $\begin{array}{l}\text { Strong oxidizing } \\
\text { agent used in } \\
\text { polymer chemistry } \\
\text { such polyaniline } \\
\text { preparation }\end{array}$ \\
\hline $\begin{array}{l}\text { Hydrochloric } \\
\text { acid }\end{array}$ & $\mathrm{HCl}$ & $400 \mathrm{ml}$ & $\begin{array}{l}\text { It consists of non- } \\
\text { corrosive and non- } \\
\text { reactive chloride ion }\end{array}$ \\
\hline Formic acid & $\mathrm{HCOOH}$ & $1000 \mathrm{ml}$ & $\begin{array}{l}\text { the protonation of the } \\
\text { PANI at the amine } \\
\text { site on the of the } \\
\text { polymer chain }\end{array}$ \\
\hline Acetonitrile & $\mathrm{C}_{2} \mathrm{H}_{3} \mathrm{~N}$ & $1000 \mathrm{ml}$ & $\begin{array}{l}\text { Used as a cleaning } \\
\text { agent to prevent } \\
\text { corrosion }\end{array}$ \\
\hline Copper sheet & $\mathrm{Cu}$ & - & - \\
\hline
\end{tabular}

Polyaniline was synthesized chemically using aniline monomer and ammonium persulphate $\left[\left(\mathrm{NH}_{4}\right)_{2}\right.$ $\mathrm{S}_{2} \mathrm{O}_{8}$ ] used as oxidant in a ratio of $4: 1$ for monomer/ 
Table 1 Surface properties of copper sheet

\begin{tabular}{llllllll}
\hline Material & $\begin{array}{l}\text { Density } \\
\left(\mathrm{g} / \mathrm{cm}^{3}\right)\end{array}$ & $\begin{array}{l}\text { Melting } \\
\text { point }\left({ }^{\circ} \mathrm{C}\right)\end{array}$ & $\begin{array}{l}\text { Electrical } \\
\text { resistivity }(\mu \Omega- \\
\mathrm{cm})\end{array}$ & $\begin{array}{l}\text { Specific heat } \\
(\mathrm{kJ} / \mathrm{kg} \mathrm{K})\end{array}$ & $\begin{array}{l}\text { Thermal } \\
\text { conductivity }(\mathrm{W} / \\
\mathrm{mK})\end{array}$ & $\begin{array}{l}\text { Thermal } \\
\text { expansion }(\mu \mathrm{m} / \\
\mathrm{mK})\end{array}$ & $\begin{array}{l}\text { Young's } \\
\text { modulus } \\
(\mathrm{GPa})\end{array}$ \\
\hline $\begin{array}{l}\text { Copper } \\
\text { sheet }\end{array}$ & 8.96 & 1085 & 1.673 & 0.39 & 401 & $\begin{array}{l}\text { Boiling } \\
\text { point }\left({ }^{\circ} \mathrm{C}\right)\end{array}$ \\
\hline
\end{tabular}

Table 2 XRD parameters for pure PANI and PANI-coated layer

\begin{tabular}{lllllllll}
\hline Sample & $2 \theta\left(^{\circ}\right)$ & $\beta\left(^{\circ}\right)$ & $D(\mathrm{~nm})$ & $d(\mathrm{~nm})$ & $\varepsilon$ & $\delta$ & $g$ & $R$ \\
\hline Pure PANI & 21.66 & 0.183 & 43.280 & 0.409 & 0.0008 & $5.339 \times 10^{14}$ & 0.0124 & $5.12 \times 10^{-1}$ \\
PANI-coated layer & 21.95 & 0.573 & 13.822 & 0.404 & 0.0025 & $5.234 \times 10^{15}$ & 0.0369 & $5.06 \times 10^{-1}$ \\
\hline
\end{tabular}

oxidant. $40 \mathrm{ml}$ of the aniline monomer was dissolved in $80 \mathrm{ml}(1 \mathrm{M} / \mathrm{L}) \mathrm{HCl}$ under ice bath below $15^{\circ} \mathrm{C}$. In parallel, $320 \mathrm{ml}$ of $1 \mathrm{M} / \mathrm{L} \mathrm{HCl}$ was dissolved in $24 \mathrm{~g}$ $\left[\left(\mathrm{NH}_{4}\right)_{2} \mathrm{~S}_{2} \mathrm{O}_{8}\right]$. The solution containing $\left[\left(\mathrm{NH}_{4}\right)_{2} \mathrm{~S}_{2} \mathrm{O}_{8}\right]$ was carefully and slowly added dropwise into the solution containing aniline for a period of $1 \mathrm{~h}$ under constant stirring. The mixture was continuously stirred for another $45 \mathrm{~min}$. The mixture was kept in a room temperature for $24 \mathrm{~h}$ to fully polymerize. The fully polymerized solution was filtered and washed with distilled water, followed by $1 \mathrm{M} \mathrm{HCl}$ solution. The obtained solid polymer was dried in an oven for $24 \mathrm{~h}$ [21]. The surface properties of the copper sheet are tabulated in Table 1.

\section{Preparation of PANI colloidal suspension}

Stock solution $(1 \mathrm{mg} / \mathrm{mL})$ of formic acid $(\mathrm{HCOOH})$ and PANI was prepared. PANI powder was dissolved in $\mathrm{HCOOH}$ aqueous solution and stirred under stirrer for $15 \mathrm{~min}$ for uniform mixture. Colloidal suspension of PANI was then prepared by dissolving $35 \mathrm{ml}$ of the stock solution into $15 \mathrm{ml}$ of acetonitrile to obtain $50 \mathrm{mg} / \mathrm{mL}$. The mixture was sonicated for $5 \mathrm{~min}$ to fully dispersed the PANI colloids [22]

\section{Sample preparation for EPD}

A copper sheet of $99 \%$ purity that is $1 \mathrm{~mm}$ thick was purchased from a local market in Alexandria, Egypt. The sheets were cut at $4 \mathrm{~cm} \times 1 \mathrm{~cm}$, length by width, respectively. These sheets were polished manually with a grit paper made from silicon carbide (grit size range 2000) to give a smooth surface and also to remove an oxide layer and also to activate the surface for electron activity during the EPD process. The sheets were sonicated using (model: 08895-83, ColeParmer, USA) in acetone for $20 \mathrm{~min}$, rinsed with copious amount of distilled water, and finally dried in a room temperature [23].

\section{EPD of PANI suspension on copper sheet}

During the electrophoretic deposition process, the prepared PANI was first dispersed in formic acid and acetonitrile under ultrasonication (Probe sonicator) for $15 \mathrm{~min}$. PANI nanoparticles were completely dispersed in formic acid and acetonitrile, forming deep green colloidal suspension. The potential of the colloidal suspension measured using Zeta-sizer analyser (3000HSa, Malvern Instruments Ltd., UK) was positive potential $(+32.9 \mathrm{mV})$. Consequently, cathodic electrophoretic deposition process shown in Fig. 1 was used for coating PANI on the $\mathrm{Cu}$ sheet electrode. A copper sheet $(1.5 \mathrm{~cm} \times 2 \mathrm{~cm})$ was used 
Figure 1 Schematic of the PANI colloidal suspension preparation steps.
Figure 2 Schematic of electrophoretic deposition process for coating polyaniline suspension on copper.
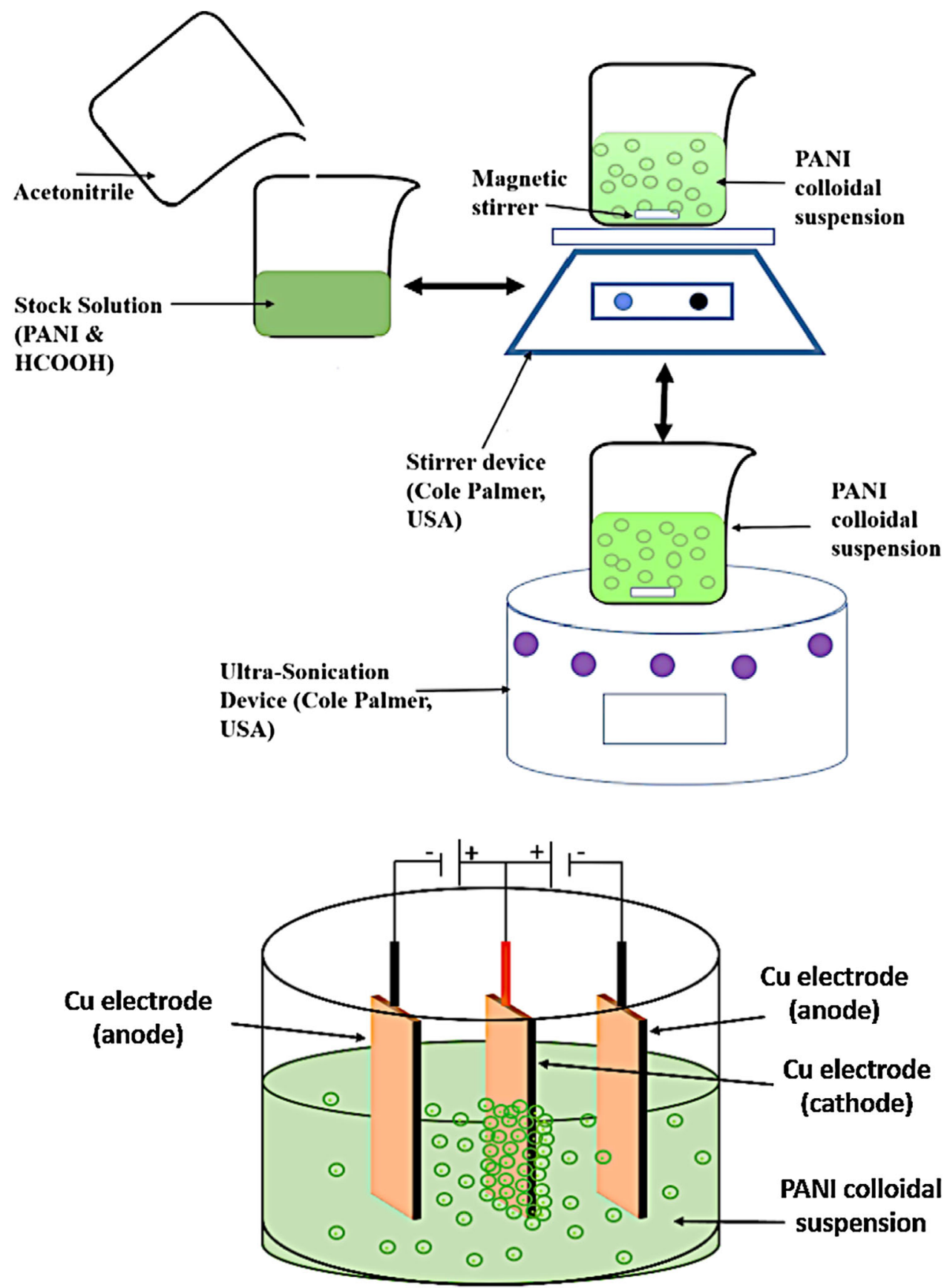

as the cathode, and two sheets of the sizes were used as the anode. This is due to the fact that both sides of the sheet were deposited by the PANI colloidal suspension. The three electrodes were immersed vertically in 150-ml beaker containing the colloidal suspension with a standard distance of $1 \mathrm{~cm}$ separated between each of the electrodes and connected to a DC power supply (Model: TB160V22A1080W,
Matsusada, Japan) as shown in Fig. 2. Consequently, the electrophoretic deposition (EPD) process was conducted using various conditions at different deposition times and applied voltages. The deposition time was fixed at $180 \mathrm{~s}$ when the voltage applied was adjusted and fixed at $15 \mathrm{~V}$ [24]. The coated dark green samples were dried at room temperature overnight [24, 25] 


\section{Characterization}

High-resolution transmission electron microscopy (HRTEM)

Samples of the polyaniline were ultrasonically dispersed in acetone for $1 \mathrm{~h}$, and a drop of the attained suspension was placed on a carbon-coated $\mathrm{Cu}$ grid. This was left overnight to stand before carrying out the test. High-resolution transmission electron microscopy (HR-TEM) imaging was performed using a JEOL JEM-2100F, Japan, operating at an accelerated voltage of $120 \mathrm{kV}$ with an iron slicer of EM-0900IS magnification of $1,100,000$.

\section{Scanning electron microscopy (SEM)}

Scanning electron microscopy (SEM) analysis was assessed by (JEOL JSM-6010LV) electron microscope. Powder samples of the polyaniline were deposited on a carbon tape, and the surface morphology of the PANI powder was taken at room temperature. The applied voltage was $15-20.0 \mathrm{kV}$, and a multi-segment backscattered electron detector (BSED) was selected to elastically detect scattered electrons.

\section{$X$-ray diffraction $(X R D)$}

The samples were characterized by powder X-ray diffraction (XRD) using a Shimadzu XRD-6100 instrument. The test was carried out in the $2 \theta$ range of $10^{\circ}-100^{\circ}$ scanning range with $0.02 \% / \mathrm{min}$ step. The phase identification of the fine powdered composite and polymer is performed with nickel filter $\mathrm{Cu} \mathrm{k}$ radiation $\left(=1.5414 \AA\right.$ ) in two ranges from $20^{\circ}$ to $70^{\circ}$.

\section{Fourier transform infrared (FT-IR) spectra}

Fourier transform infrared (FT-IR) spectra were introduced in analysing the chemical composition of the synthetic PANI sample. The polyaniline powder deposited on silicon windows was recorded in the range of $400-4000 \mathrm{~cm}^{-1}$ at 64 scans per spectrum at $2 \mathrm{~cm}^{-1}$ resolution using a fully computerized Thermo Nicolet Bruker Vertex 70 (Smart Orbit ATR accessory with diamond crystal) FT-IR spectrometer with spectra range from 8000 to $350 \mathrm{~cm}^{-1}$ and narrow band MCT detector, liquid $\mathrm{N}_{2}$ cooled. An absorption subtraction technique was applied to remove the spectral features of the silicon substrate. Spectra were corrected for the moisture and carbon dioxide in the optical path and collected over 32 scans. The samples were powdery polyaniline for the FT-IR test.

\section{Ultra-violet spectrum}

The Ultraviolet-Visible spectroscopy (UV-Vis) spectrum of the polyaniline in organic solution was recorded using Hitachi U-3900 equipped with double-beam single-monochromator system. The wavelength range of 190-900 $\mathrm{nm}$ with a band pass from 0 to $5 \mathrm{~nm}$ detects single photomultiplier to determine the band gap and various functional groups within the liquid powder molecules.

\section{Anti-corrosion assessment}

The performance of the PANI-EPD-coated copper sheet against corrosion was carried out by potentiodynamic (Tafel) polarization method using Gamry Potentiostat (reference 3000, Gamry instrument) in $3.5 \% \mathrm{NaCl}$ solution. In this setup, three cells (threeelectrode cells) were used where the coated copper sheet acts as working electrode with an exposed area of $4 \mathrm{~cm}^{2}$ immersed in the $3.5 \% \mathrm{NaCl}$ solution, $\mathrm{Ag} /$ $\mathrm{AgCl}$ filled with $\mathrm{KCl}$ as reference electrode, and graphite as counterelectrode. These three electrodes were immersed in the electrolyte, and the electrodes were connected to the potentiostat to record an opencircuit potential till the electrolyte stabilized. The open-circuit potential (OCP) was monitored until it attained a steady state. Tafel polarization curve was determined just after OCP sample in the $3.5 \% \mathrm{NaCl}$ for $1 \mathrm{~h}$. The anodic and the cathodic polarization was performed at -0.25 to $0.25 V_{\text {sce }}$ at a scan rate of $0.1 \mathrm{mV} / \mathrm{s}$. Corrosion potential $\left(E_{\text {corr }}\right)$, corrosion current density $\left(I_{\text {corr }}\right)$, and corrosion rate $(\mathrm{CR})$ were calculated from the polarization curve accordingly.

\section{Results and discussion}

\section{Mechanism of PANI suspension for EPD}

The prepared PANI was utilized to prepare the colloidal suspension in the presence of formic acid (HCOO) and acetonitrile. The PANI in the emeraldine form (base) was initially dissolved in the formic acid forming a stock solution after sonication. Dispersion was formed from the stock solution using 
the acetonitrile and sonicated for $20 \mathrm{~min}$, thereby forming a suspension of colloids. The rationale behind utilizing these mixtures for the suspension is that there is solubility of formic acid in PANI in the emeraldine base form; as a result, the formic acid isolates the random chains of the PANI which has intertwined and breaks down the PANI in its chains level. The proton addition to the polymer's atom at its amine site on the polymer chains concurrently is carried out by the HCOO, consequently transforming PANI from emeraldine base to a conducting emeraldine salt. Notwithstanding this, there is solubility of acetonitrile $\left(\mathrm{C}_{2} \mathrm{H}_{3} \mathrm{~N}\right)$ in $\mathrm{HCOO}$ but not in PANI. Consequently, dispersing $\mathrm{C}_{2} \mathrm{H}_{3} \mathrm{~N}$ in $\mathrm{HCOO}$ dissipate as a result the $\mathrm{HCOO}$ shrinks in size into the medium of its surrounding. This causes compression of the chains inside the polymer in spherical shape, and the polymer starts to split up in the di-electric medium into ions simultaneously. Thus, rendering the colloids of the polymer carrying positive charges and also due to the electrostatic repulsion occurring between the spherical particles causes the stability of the colloidal suspension as shown in Fig. 3.

\section{Morphological investigations of PANI}

The TEM image was employed to evaluate the structural and morphological features of the produced PANI. In general, Fig. 4 depicts the production of PANI with nanofibre morphology that is twisted and agglomerated into an interconnected network, rather than bundle. The image explains very clearly that the PANI has a typical 3D structure with a wrinkled morphology. The dark areas point to the

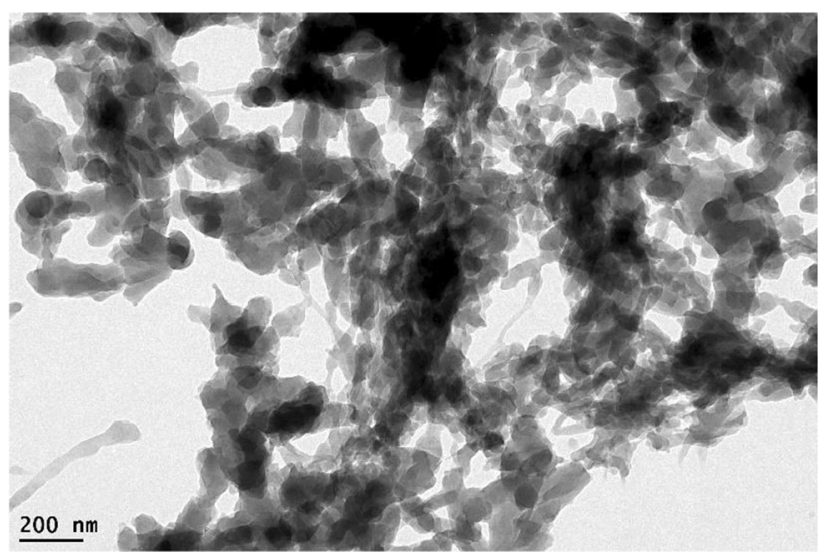

Figure 4 TEM image of the pure PANI powder.

multilayer PANI, while low-density layers result from the nanostructure exfoliation highlighted by the transparent areas. Notwithstanding these, the dark areas are more visible and this shows that most layers of the PANI are well exfoliated.

Morphological and particle size analysis were carried out on the synthesized organic acid. PANIdoped thin films were investigated with scanning electron microscopy (SEM) micrographs from 10 to 25 $\mathrm{Kx}$ magnification separating the images along with accelerating a voltage of $20 \mathrm{kV}$, and their respective photographs are illustrated in Fig. 4. Considering the SEM images, all the PANI thin films exhibit a homogenous phase with uniform matrix [26] with Fig. 5a depicting SEM image of the polished copper substrate at $X 40$ magnification. Figure $5 b$ that was taken at X 5000 magnification demonstrates the SEM image of pure PANI powder with an irregular busted small inured piece of ice rock and also appears like a

Figure 3 Formation of polyaniline colloids by dispersing polyaniline/formic acid solution into acetonitrile.

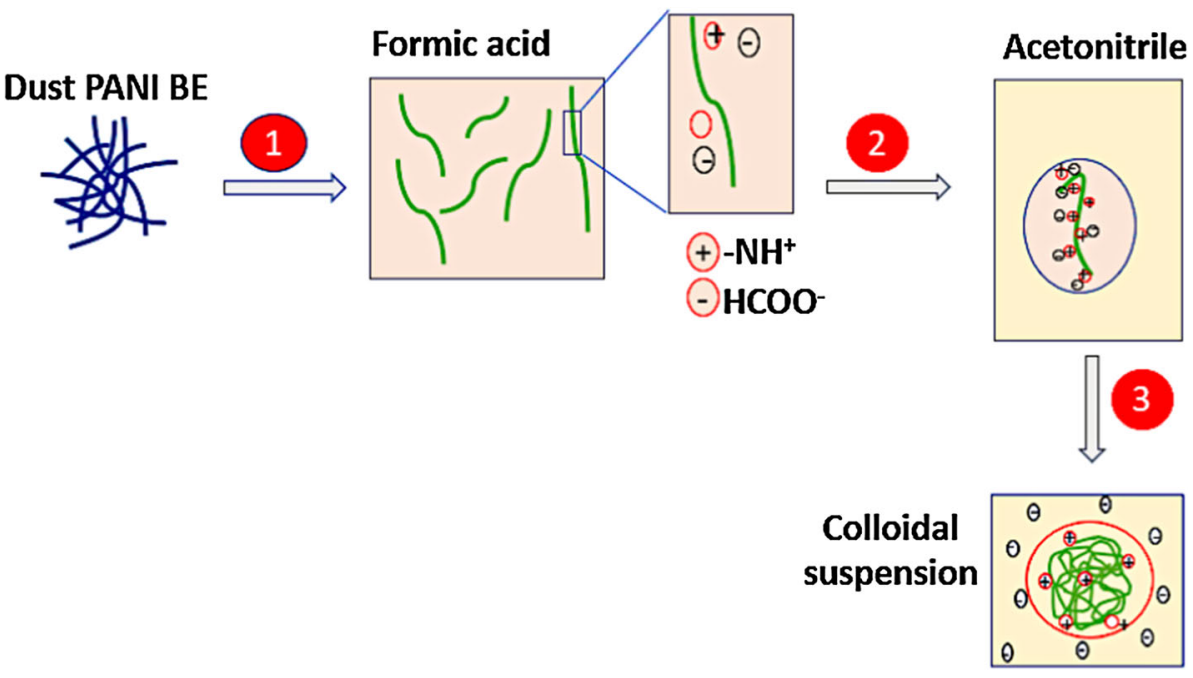



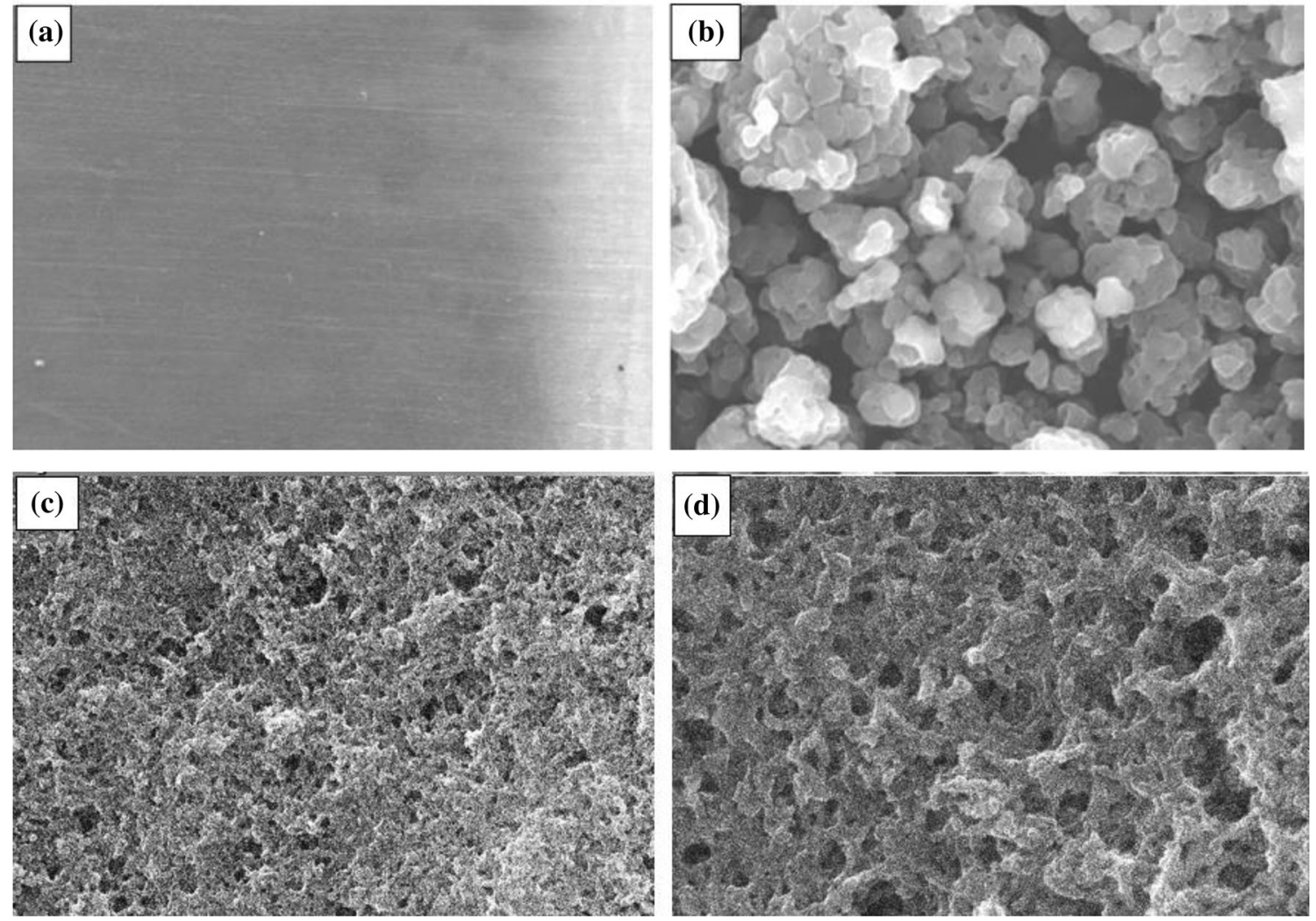

Figure 5 SEM images for a bare copper, $\mathbf{b}$ pure PANI powder, $\mathbf{c}-\mathbf{d}$. PANI-coated layers.

coral reef surface morphology with $12 \mu \mathrm{m}$ as the size of the particle. The PANI-coated layers in Fig. 5c, which were in the same magnification scale of Fig. 5b, appeared as a dense speck colossal structure with irregular broken ice rock-like morphology with $5 \mu \mathrm{m}$ dimension. Notwithstanding these, the PANIcoated layer with $1-\mu \mathrm{m}$ scale exhibits a characteristic of layer-by-layer twisted fibre with some tiny particles as shown in Fig. 5d, which was taken at X 10,000 magnification. Considering the SEM images, we could observe different morphologies for Fig. 5b-d. This is as a result of the formic acid and the acetonitrile that causes the PANI powder to be stable and forms colloids for the EPD process. The formic acid separates the random chains of the PANI and protonation which occurs at the amine site on the polymer chain causing changes in PANI'S morphology. Acetonitrile effect on causing formic acid to shrink into its surrounding causes the compression of the PANI chains in spherical shape which amounts to the breakup of the PANI into ions in the dielectric medium. Consequently, charging the PANI colloids being positively as a result of the electrostatic force of repulsion occurring between these spherical particles

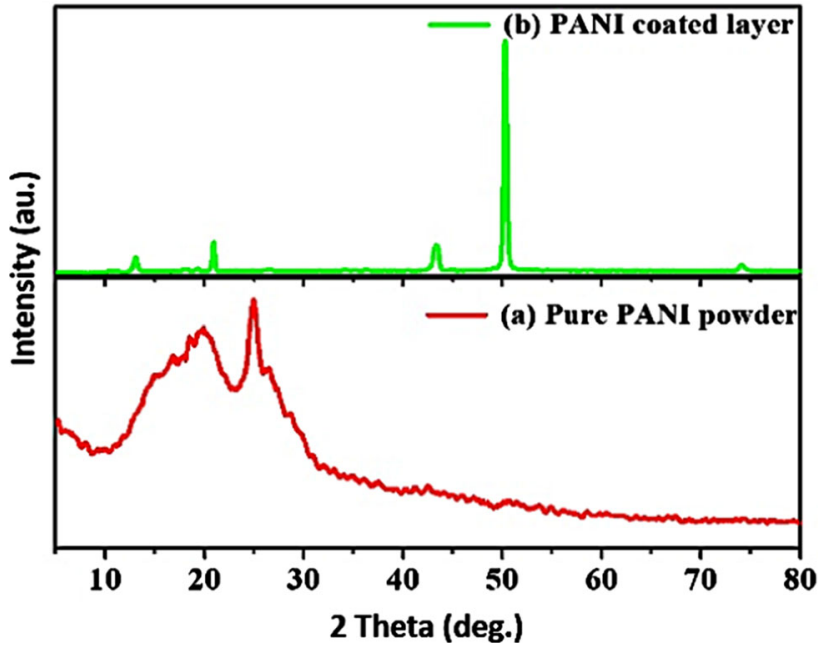

Figure 6 XRD pattern for a pure PANI powder and $\mathbf{b}$ PANIcoated layer.

also alters the morphological properties of the PANI. Nevertheless, the obtained image is in accordance with the results obtained by $[27,28]$. 


\section{X-ray diffraction of PANI samples}

Figure 6 shows the XRD patterns for pure PANI powder and PANI-coated layer on copper substrate. The observed diffraction peaks are $2 \theta=15^{\circ}, 21^{\circ}, 25^{\circ}$, $44^{\circ}, 53^{\circ}, 74^{\circ}$ which correspond to (011), (020), (200), (022), (213), (222), respectively $[29,30]$. The patterns of the XRD as observed are analogous to the ICDD data number 00-053-1891 confirming the formation of polyaniline emeraldine salt in a doped form. As a result of murkiness in the chains of the polymer, it appears semi-crystalline [31] or amorphous [32] in nature dependent on experimental conditions. The semi-crystalline polymers exhibit well and tighter arrangement of its molecular chains which combines the strength of crystalline polymers with the noncrystalline flexibility. The observed intense or sharp peaks of the XRD patterns correspond to the region of crystallinity while the broader peaks show the region of non-crystallinity in the chain of the polymers. The semi-crystallinity is observed as a result of the repetitive arrangement of the quinoid and the benzenoid rings in the polymer chain. This result has been reported by Butoi et al. [33], Olivera et al. [34], Mitra et al. [35], and Elnagar et al. [30]. The observed peaks at $2 \theta=53^{\circ}$ and $74^{\circ}$ are due to the presence of the metallic substrate. The XRD peaks at $2 \theta=21^{\circ}$ for the two samples, the structural parameters, namely micro-strain $(\varepsilon)$, interplanar distance $(d)$, dislocation density $(D)$, interchain separation $(R)$, and distortion parameter $(g)$, were calculated using the following five formulae. The results are summarized in Table 2.

$d=\frac{\lambda}{2 \sin \theta}$

$\varepsilon=\frac{\beta \cos \theta}{4}$

$\delta=\frac{1}{D^{2}}$

$g=\frac{\beta}{\tan \theta}$
Table 4 IR frequencies of PANI powder

\begin{tabular}{lc}
\hline IR frequencies, $\mathrm{cm}^{-1}$ & \\
\hline & PANI $\left(\mathrm{cm}^{-1}\right)$ \\
\hline $\mathrm{N}-\mathrm{H}$ & 1700 \\
$\mathrm{C}=\mathrm{C}$ benzenoid & 1550 \\
$\mathrm{C}=\mathrm{N}$ quinoid & 1600 \\
$\mathrm{C}-\mathrm{N}$ quinoid amine & 1300 \\
$\mathrm{C}_{6} \mathrm{H}_{6}$ ring & 1150 \\
Ortho substitution & 782 \\
$\mathrm{C}-\mathrm{H}$ & 740 \\
$\mathrm{C}-\mathrm{C}$ & 650 \\
\hline
\end{tabular}

$R=\frac{5 \lambda}{8 \sin \theta}$

From Table 3, it is evidenced that an increase in the number of cycles, microstrain, and interplanar distance decreases the size of crystallites. As the deposition of cycles increases, the reconstruction of the molecules/atoms takes place resulting in a decrease in the size of the crystals. Also, as the size of the crystals decreases, full width at half maximum, $\beta$ (FWHM), increases with an increment in the number of cycles. Lattice misfit results in the production of micro-strain, $\varepsilon$, dependent on the condition of growth [36]. Interplanar distance and micro-strain thus increased in PANI-coated layer compared to the pure PANI powder. Increase in the number of cycles increases the density of the atom/molecules causing internal stress which introduces deformations in the materials. Dislocation thus occurs when deformation increases. Relatively high structural disorders and defects in the PANI-coated layer sample promoted better process of oxidation-reduction. Quite a number of researchers have reported a better electrochemical performance for an active material of small crystal size coupled with structural defects and disorders [37, 38], but our results are in agreement with the research done by Suman et al. [39].

Table 3 XRD analysis of PANI powder

\begin{tabular}{llllrr}
\hline $2 \theta$ & $10.83^{\circ}$ & $21^{\circ}$ & $25.70^{\circ}$ & $53.90^{\circ}$ & $74.60^{\circ}$ \\
\hline hkl (plane) & 011 & 020 & 200 & 213 & 222 \\
\hline
\end{tabular}




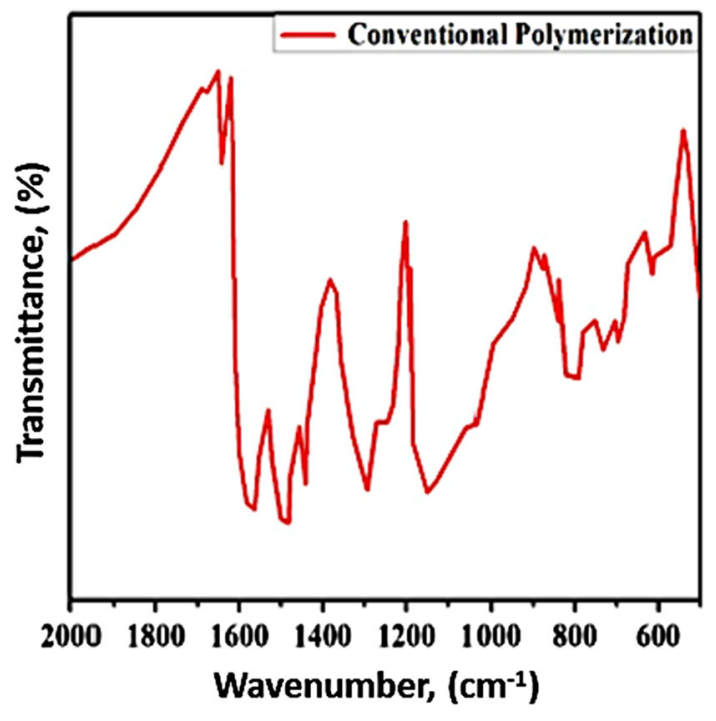

Figure 7 FT-IR spectra of polyaniline powder.

\section{FT-IR analysis of PANI samples}

Fourier transform infrared spectroscopy (FT-IR) is the spectroscopic technique widely used in analysing the polymers [40]. They are of great importance since the FTIR could collect the infrared spectrum information of polymers and provide the structural information to identify the molecules. The FTIR spectroscopy could provide detailed chain structure information of polymers [41, 42]. The spectrum of FT-IR of polyaniline is shown in Fig. 7. The main characteristic properties of the polyaniline bands follow [43]: the band at approximately $1700 \mathrm{~cm}^{-1}$ is because of stretching of $\mathrm{N}-\mathrm{H}$ mode, $\mathrm{C}=\mathrm{C}$ and $\mathrm{C}=\mathrm{N}$ stretching modes for benzenoid and quinoid rings occurring at approximately $1550 \mathrm{~cm}^{-1}$ and $1600 \mathrm{~cm}^{-1}$, respectively [44-46]. C-N stretching vibrations of the quinoid imine site units' band are at approx. $1300 \mathrm{~cm}^{-1}$. In this region, a characteristic band of the conducting polyaniline protonation appears as well indicating a characteristic of emeraldine salt (ES) phase of polyaniline. The bands between 850 and $825 \mathrm{~cm}^{-1}$ correspond to the vibrational flexions out of the $\mathrm{C}-\mathrm{H}$ bonds plane [44]. The band at approximately

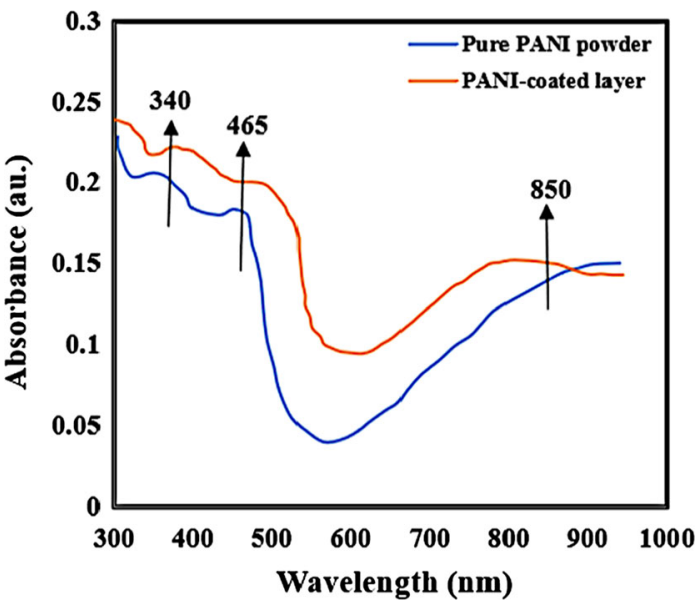

Figure 8 UV-spectra of polyaniline and PANI-coated layer.

$1150 \mathrm{~cm}^{-1}$ is assigned to $1-4$ substitution on the benzene ring. The bands at $782 \mathrm{~cm}^{-1}$ show ortho substitution. Finally, vibrations of the bonds, C-C and $\mathrm{C}-\mathrm{H}$, in the aromatic ring appears at $740-650 \mathrm{~cm}^{-1}$ [45]. The spectra of the FT-IR study show that polymerization of the aniline monomer occurred and resulted in the formation of the polyaniline. Table 4 shows the peaks observed for polyaniline.

\section{UV-Vis analysis of PANI samples}

The UV-Visible spectrum of the polyaniline was recorded using Hitachi U-3900 double-beam spectrophotometer in the range of 300-900 nm. Electronic spectra of polyaniline were recorded by dispersing the polyaniline in organic solvent with an ultrasonication. Electronic absorption of the conducting polymer is useful in investigating the oxidation and doping state of the polymer backbone. The optical absorption spectra of the polyaniline and PANIcoated layer are presented in Fig. 8 depicting the absorbance as a function of wavelength $(\mathrm{nm})$ derived from a graph appearing with two peaks. Polyaniline peak at wavelength of $340 \mathrm{~nm}$ corresponds to the $\pi-$ $\pi^{*}$ [47] transition of the benzenoid rings. The second peak appearing at a wavelength of $310 \mathrm{~nm}$ is due to

Table 5 Tafel curves parameters for bare copper and EPD-PANI-coated film of polyaniline

\begin{tabular}{|c|c|c|c|c|c|c|c|c|}
\hline Sample & $I_{\text {corr }}\left(\mathrm{A} / \mathrm{cm}^{2}\right)$ & $\mathrm{E}_{\text {corr }}(\mathrm{mV})$ & $\beta_{a}(\mathrm{~V} / \mathrm{dec})$ & $\beta_{c}(\mathrm{~V} / \mathrm{dec})$ & $R_{\mathrm{p}}\left(\Omega \mathrm{cm}^{2}\right)$ & CR (mpy) & $P(\%)$ & IE $(\%)$ \\
\hline Bare copper & $6.020 \times 10^{-6}$ & -259 & 0.0589 & 0.1672 & $3.142 \times 10^{3}$ & 12.72 & - & - \\
\hline PANI-coated layer & $426 \times 10^{-9}$ & -199 & 0.0497 & 0.0371 & $2.165 \times 10^{4}$ & 0.1006 & 1.46 & 92.92 \\
\hline
\end{tabular}


the $\pi-\pi^{*}$ transition from the nitrogen oxide containing nonatomic electrons to the conducting polymer, while the shoulder at $465 \mathrm{~nm}$ is attributed to the localized polarons which are characteristic of the protonated polyaniline [48]. The broad band increases the absorption band at a higher wavelength at $800 \mathrm{~nm}$ in approximation with a free tail carrier confirming the existence of conducting form of emeraldine salt (ES) of the PANI [49].

\section{Zeta potential and particle analysis}

Electrophoretic mobility is a measurement used to determine the zeta potential value which depends on the nanoparticles and the medium property [50]. Zeta potential controls the deposition type and its velocity [51]. Determination of suspension's stability depends largely on zeta potential value. Suspensions with zeta potential are more than either $+30 \mathrm{mV}$ or $-30 \mathrm{mV}$ [52] because of the polyaniline functional groups [sulphonated poly(aniline-co-o-aminophenol), s-copolymerl; the zeta potential value of the polyaniline attained a positive charge as a result of the functional group; and confirmation was made via measurement of the zeta potential and was equal to $+32.9 \mathrm{mV}$ as shown in Fig. 9. This caused the colloidal suspension during EPD process to be deposited on the copper sheet of the cathode. The value also indicates the stability of the suspension [53]. Particle size distribution shown in Fig. 10 indicates $545.2 \mathrm{~nm}$ as the average particle size.

\section{Anticorrosion performance}

Potentiodynamic polarization analysis was used to extrapolate the rate of corrosion of the PANI-coated specimen in $3.5 \mathrm{wt} \% \mathrm{NaCl}$. Open-circuit potential,
$\mathrm{OCP}$, and Tafel polarization curves of the bare $\mathrm{Cu}$ and PANI-coated $\mathrm{Cu}$ are shown in Figs. 11, 12, respectively. EPD-PANI indicated a significant decrease in the cathodic and the anodic currents. This confirms the protection of PANI to the copper. The shift in corrosion potential from - 259 to $-199 \mathrm{mV}$ indicating the cathodic barrier PANI provided, consequently, decreasing the tendency of the copper corroding by the release of electrons. Table 5 displays the calculated parameters from the Tafel polarization curves with its respective corrosion potential $\left(E_{\text {corr }}\right)$, corrosion current $\left(I_{\text {corr }}\right)$, and the corrosion rate. The corrosion rate $(0.1006 \mathrm{mpy})$ recorded for the coated $\mathrm{Cu}$ sample was higher in magnitude as compared to the corrosion rate of the bare copper with a value of 1.422 mpy, which indicates the absorption of the PANI's colloidal suspension onto the surface of the $\mathrm{Cu}$, thereby inhibiting the occurrence of corrosion. Additionally, the $\pi$-electrons of the heteroatoms and the aromatic rings of the polyaniline which contains lone pairs of electrons: oxygen $(\mathrm{O})$ and nitrogen $(\mathrm{N})$ atoms, were contributory factors for the strong absorption and adhesion of the PANI onto the $\mathrm{Cu}$, which led to the efficient resistance of the $\mathrm{Cu}$ in the corrosive media. EPD-PANI recorded low corrosion rate at 0.1006 Mils per year (mpy) compared to the corrosion rate of the copper (1.422 mpy) with positive in corrosion potential of $60 \mathrm{mV}$ compared to the bare copper. The corrosion potential shows its susceptibility to corrosion, but the positive demonstrates the corrosion resistance of the copper as a result of the PANI coating at the expense of chlorine ions $\left(\mathrm{Cl}^{-}\right)$ albeit speeding the dissolution of the copper [54]. The presence of the polymer on the surface of the conducting substrate decreased the activity of the $\mathrm{Cl}^{-}$in reaching the surface of the metal, consequently
Figure 9 Zeta potential distribution in formic acid and acetonitrile.

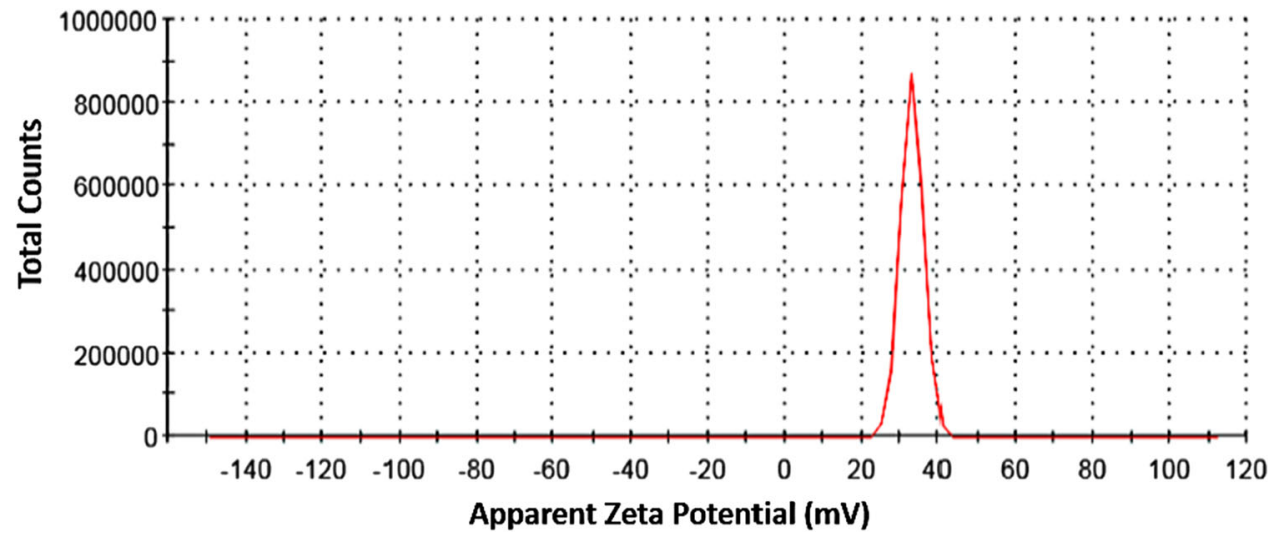


Figure 10 Particle size distribution of PANI.

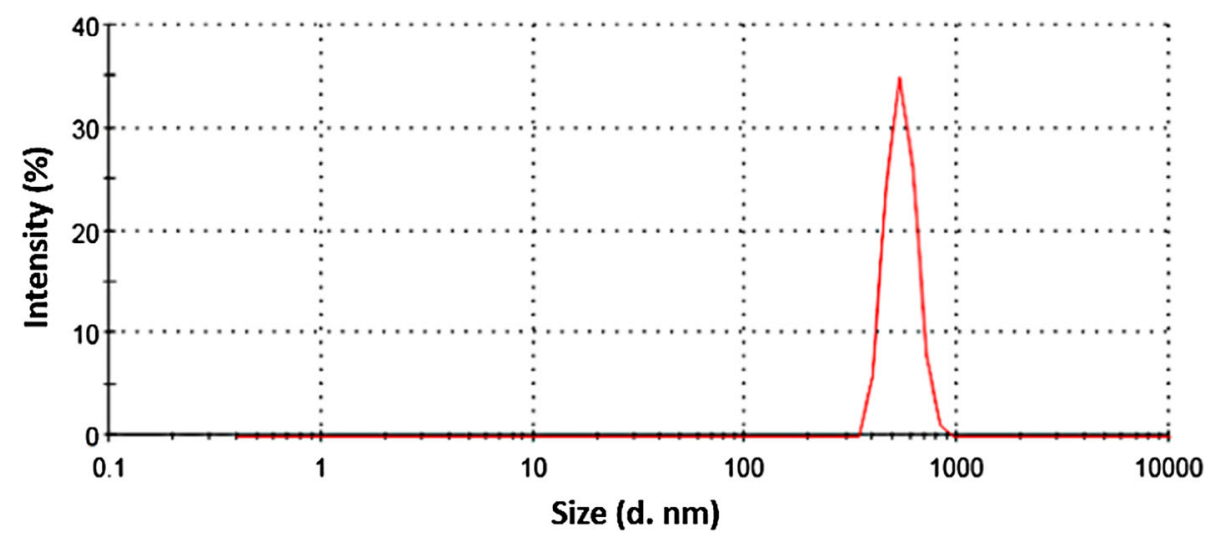

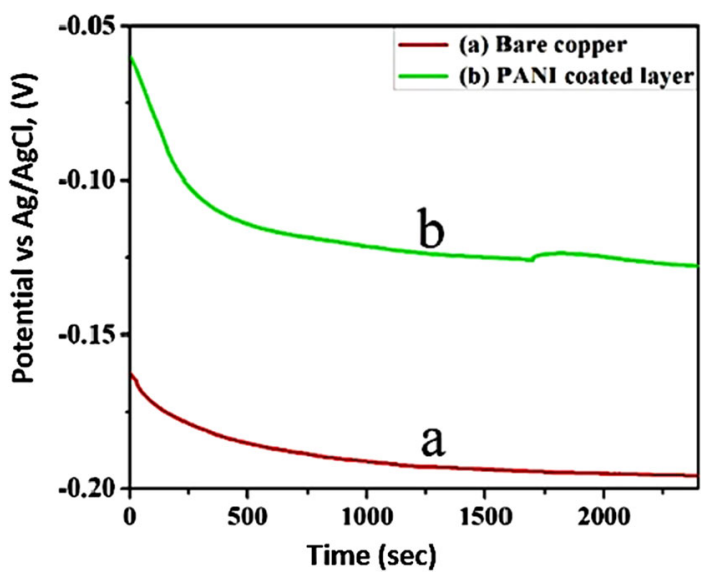

Figure 11 Open-circuit potential a bare $\mathrm{Cu}, \mathbf{b}$ PANI-coated $\mathrm{Cu}$.

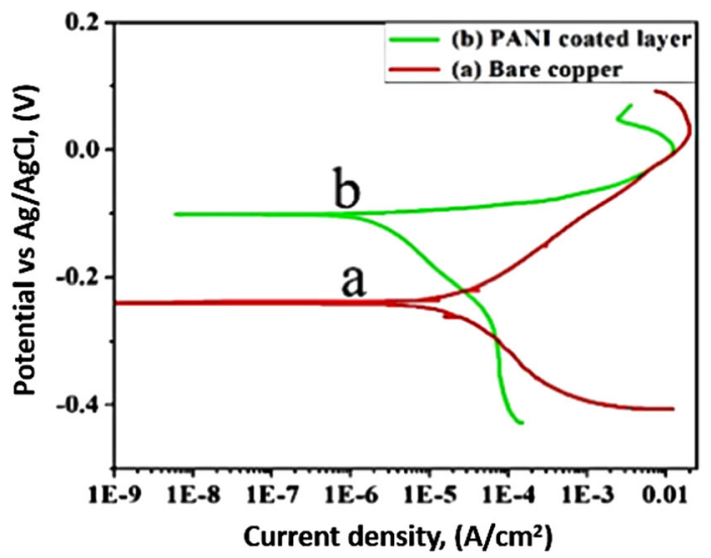

Figure 12 Tafel polarization a bare $\mathrm{Cu}$, b PANI-coated $\mathrm{Cu}$.

decreasing the rate of metal dissolution in the electrolyte.

The ability for the EPD-PANI protecting the metal from corroding in the electrolyte is because of the structure of the coating which is less distorted and the hydrophobic nature as a result resisting the saline electrolyte from permeating. In addition, good adhesion of EPD-PANI coating as confirmed by SEM (Fig. $5 b$ ) could be a factor in enhancing the resistance of the copper to corrosion by preventing the penetration of the $\mathrm{Cl}^{-}$via the interface between the coating and the bare copper. The significantly enhanced performance of the EPD-PANI coatings is due to better adhesion and the coatings hydrophobic nature compared to other coating techniques. Observation could be made from Table 5 that the anodic slope $\left(\beta_{a}\right)$ of EPD-PANI coatings was much higher than that of the bare copper suggesting more adsorption of $\mathrm{Cl}^{-}$ ions on the PANI-coated layer than the bare copper. The corrosion process involves two half reactions: anodic and the cathodic reactions. During anodic reaction, oxidation of $\mathrm{Cu}$ occurs releasing electrons which forms soluble $\mathrm{Cu}^{2+}$ represented in equation [55].

$\mathrm{Cu} \rightarrow \mathrm{Cu}^{2+}+2 \mathrm{e}^{-}$

Other reactions could also take place in $\mathrm{NaCl}$ solution during the process

$\mathrm{Cu}+2 \mathrm{Cl}^{-} \rightarrow \mathrm{CuCl}^{-2}+2 \mathrm{e}^{-}$

On the cathode surface, reduction reaction occurs in which electrolyte such as $\mathrm{O}_{2}$ or $\mathrm{H}^{+}$is reduced, eliminating electrons from the copper according to the reaction

$$
\begin{aligned}
& 2 \mathrm{H}^{+}+2 \mathrm{e}^{-} \rightarrow \mathrm{H}_{2} \\
& \mathrm{O}_{2}+2 \mathrm{H}_{2} \mathrm{O}+4 \mathrm{e}^{-} \rightarrow 4 \mathrm{OH}^{-}
\end{aligned}
$$

According to the corrosion assumptions, transfer of electrons at the surface of the metal reactions kinetics is manipulated by the reaction rate of the anodic and the cathodic reactions. Consequently, corrosion rate (CR) between these reactions is controlled by 
Figure 13 Anti-corrosion mechanism of PANI-coated layer.

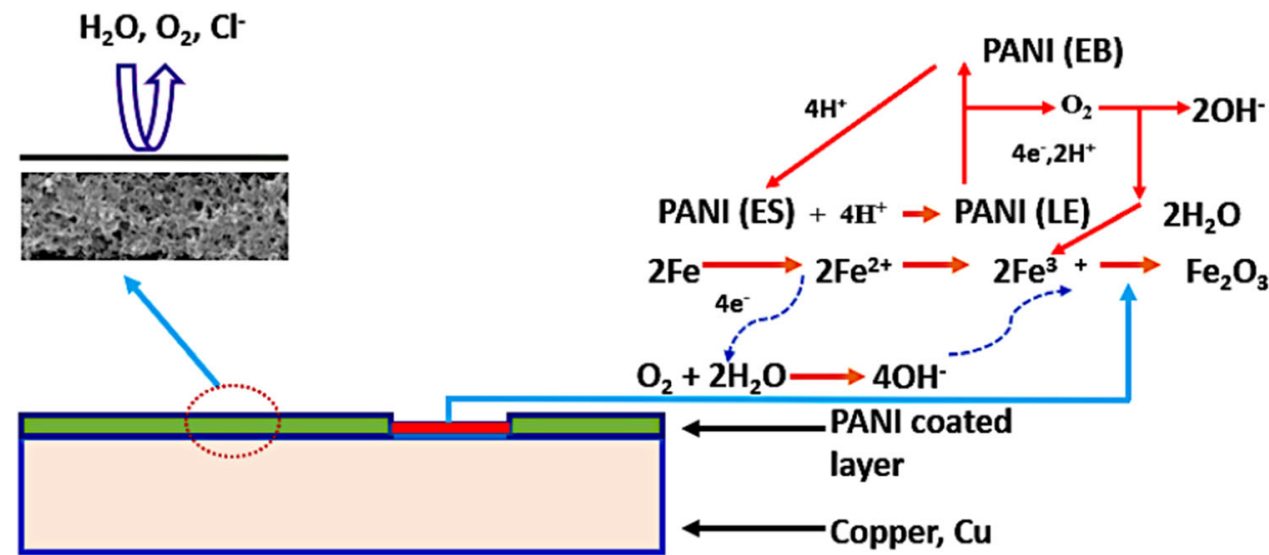

equilibrium. There is no net current that occurs when the reactions are in equilibrium [23].

$\mathrm{CR}=\frac{I_{\text {corr }} K E W}{\rho A}$

where $K=3272 \mathrm{~mm} / \mathrm{A} \mathrm{cm} \mathrm{yr}$ is a constant which defines the units of $\mathrm{CR}(\mathrm{mm} / \mathrm{yr}), \mathrm{EW}=31.7 \mathrm{~g}$ represents equivalent weight of $\mathrm{Cu}, \rho=8.97 \mathrm{~g} / \mathrm{cm}^{3}$ density of $\mathrm{Cu}$, and $A=4 \mathrm{~cm}^{2}$ area of the sample.

Furthermore, the corrosion inhibition efficiency (IE) from the Tafel polarization curves was calculated [56] using the following formula:

$\mathrm{IE}(\%)=\frac{I_{\text {corr(b) }}-I_{\text {corr(c) }}}{I_{\text {corr }(\mathrm{b})}} \times 100$

The extent of porosity is strongly governed by the corrosion resistance of the coating behaviour. It is therefore pertinent to determine the overall resistance the coating offered to the metal. Potentiodynamic polarization measurement was used to determine porosity of the EPD-PANI on the metal substrate. The following equation was adopted in calculating the polarization resistance $\left(R_{\mathrm{p}}\right)$ and percentage porosity $(P \%)$ of the coating [57].

$R_{\mathrm{p}}=\frac{\beta_{a \beta_{c}}}{2.3 I_{\operatorname{corr}\left(\beta_{a} \beta_{c}\right)}}$

where high $R_{\mathrm{p}}$ value implies high resistance of the material to corrosion and vice versa. Table 5 shows that the $R_{\mathrm{p}}$ value for the PANI-coated $\mathrm{Cu}$ has higher value compared to the bare $\mathrm{Cu}$. Polarization resistance from Table 4 reveals increment in $R_{\mathrm{p}}$ value of the PANI-coated layer $\left(2.165 \times 104 \Omega \mathrm{cm}^{2}\right)$ by a higher margin compared to the $R_{\mathrm{p}}$ value of the bare copper $\left(3.142 \times 103 \Omega \mathrm{cm}^{2}\right)$. The polarization resistance acted as a resistor, consequently preventing the electrolyte from penetrating the $\mathrm{Cu}$.

$P=\left(\frac{R_{c}}{R_{c l}}\right) \times 10^{-\left(\frac{\mid \Delta E_{\text {corr }}}{b_{a}}\right)}$

where $P$ represents total porosity, $R_{\text {puc }}$ and $R_{\mathrm{pc}}$ are, respectively, polarization resistance of bare copper and EPD-PANI-coated layer, $\Delta E_{\text {corr }}$ is the difference between corrosion potentials, and $b_{a}$ is the Tafel anodic slope of the bare copper and the PANI-coated layer. The value of the porosity calculated is presented in Table 5. It could be deduced that the value of $\mathrm{P}$ for the PANI-coated layer is very low indicating the efficacy of the coating serving as a barrier for the metal thereby decreasing the corrosion rate from 12.76 to $0.1006 \mathrm{mpy}$. The low value of the porosity in the PANI-coated layer gave rise to the enhancement of the anti-corrosion resistance thereby hindering the electrolyte access to the copper substrate.

\section{Mechanism of corrosion}

The microscopic interaction between the PANIcoated layer and the treated copper substrate increases its mechanical and adhesion properties of the coating. The PANI powder on the surface of the copper substrate provides a barrier for diffusion of $\mathrm{H}_{2} \mathrm{O}, \mathrm{O}_{2}$, and $\mathrm{Cl}^{-}$as a result of the surface of the PANI extremely rough when coated. Again, the hydrophobic nature of the pure PANI powder also prevents moisture from penetrating via the substrate surface. According to Dhanabal et al. [58], and Chen et al. [59], corrosion prevention of polyaniline occurs by forming a passivating layer of $\mathrm{Fe}_{2} \mathrm{O}_{3}$ at the metals interface and the polyaniline coating. The tendency of passivating layer forming on the surface of coating is 
more pronounced in these present experiments thus shifting of the potential more to the anodic side as compared to other coating materials. The thin coating and the protection offered by copper acted as anion storage and an electrical barrier for the PANI thereby slowing the effects of electrochemical reactions responsible for corrosion of metals. Figure 13 shows the schematic diagram demonstrating the mechanism of corrosion. These factors lead to better corrosion performance of the metals and in accordance to the intended functions [60-66].

\section{Conclusion}

This study focused on the formation of uniform PANI coatings on copper sheet as means of corrosion resistance. PANI coatings were successfully deposited on copper by means of EPD technique in acetonitrile and formic acid medium and were characterized by FTIR, XRD, SEM, UV-Vis, and TEM. The efficacy of the coating was analysed using potentiodynamic (Tafel) polarization studies. PANI coatings on the copper were found to enhance and also exhibit an excellent protection against corrosion process in an aggressive environment carried out in $3.5 \% \mathrm{NaCl}$ solution. SEM analysis was used to examine the morphology of the deposit to support the results obtained which revealed that PANI nanoparticles uniformly covered the metal surface which remained free of defect after immersion in the $3.5 \% \mathrm{NaCl}$ solution. The stability of the suspension was confirmed via the use of zeta potential $(+32.9 \mathrm{mV})$. The optimum conditions for obtaining a well-formed deposit on the substrate were achieved when the concentration of suspension was $50 \mathrm{mg} / \mathrm{ml}$. Consequently, the use of PANI as a corrosion barrier increased significantly the anticorrosion performance of the copper substrate which contributed to the formation of the layer; therefore, EPD process of depositing PANI colloidal suspension on copper sheet could be applied in an industrial environment susceptible to corrosion.

\section{Acknowledgements}

The authors would like to acknowledge the Japanese International Cooperation Agency (JICA) and EgyptJapan University of Science and Technology (E-JUST) for the financial and the technical support, respectively.

\section{Authors contribution}

MMYZ took part in conceptualization, methodology, resources, formal analysis, investigation, visualization, writing-review and editing, supervision. MF involved in conceptualization, methodology, resources, investigation, writing-original draft, writingreview and editing. ME took part in supervision. AES involved in supervision.

\section{Funding}

Open Access funding enabled and organized by CAUL and its Member Institutions.

\section{Declarations}

Conflict of interest The authors declare that they do not have any known competing financial interest that could have appeared to influence the work presented in this research paper.

Open Access This article is licensed under a Creative Commons Attribution 4.0 International License, which permits use, sharing, adaptation, distribution and reproduction in any medium or format, as long as you give appropriate credit to the original author(s) and the source, provide a link to the Creative Commons licence, and indicate if changes were made. The images or other third party material in this article are included in the article's Creative Commons licence, unless indicated otherwise in a credit line to the material. If material is not included in the article's Creative Commons licence and your intended use is not permitted by statutory regulation or exceeds the permitted use, you will need to obtain permission directly from the copyright holder. To view a copy of this licence, visit http://creativecommons.org/licen ses $/$ by $/ 4.0 /$.

\section{References}

[1] Sauvant-Moynot V, Gonzalez S, Kittel J (2008) Self-healing coatings: an alternative route for anticorrosion protection. Prog Org Coat 63(3):307-315. https://doi.org/10.1016/j.por gcoat.2008.03.004

[2] Su F, Yao K (2014) Facile fabrication of superhydrophobic surface with excellent mechanical abrasion and corrosion resistance on copper substrate by a novel method. ACS Appl 
Mater Interfaces 6(11):8762-8770. https://doi.org/10.1021/a m501539b

[3] Zhao Y, Xing C, Zhang Z, Yu L (2017) Superhydrophobic polyaniline/polystyrene micro/nanostructures as anticorrosion coatings. React Funct Polym 119(February):95-104. h ttps://doi.org/10.1016/j.reactfunctpolym.2017.08.005

[4] Zaghloul MMY, Zaghloul MMY (2017) Influence of flame retardant magnesium hydroxide on the mechanical properties of high density polyethylene composites. J Reinf Plast Compos 36(24):1802-1816. https://doi.org/10.1177/ 0731684417727143

[5] Zaghloul MMYM (2018) Mechanical properties of linear low-density polyethylene fire-retarded with melamine polyphosphate. J Appl Polym Sci 135:46770. https://doi.org/ 10.1002/app.46770

[6] Zaghloul MMYM et al (2021) Wear Behaviour of polymeric materials reinforced with man-made fibres: a comprehensive review about fibre volume fraction influence on wear performance. J Reinf Plast Compos 215-241. https://doi.org/10. 1177/07316844211051733

[7] Caldona EB, de Leon ACC, Pajarito BB, Advincula RC (2017) Novel anti-corrosion coatings from rubber-modified polybenzoxazine-based polyaniline composites. Appl Surf Sci 422:162-171. https://doi.org/10.1016/j.apsusc.2017.05. 083

[8] Donescu D et al (2017) Synthesis and magnetic properties of inverted core-shell polyaniline-ferrite composite. Appl Surf Sci 414:8-17. https://doi.org/10.1016/j.apsusc.2017.04.061

[9] Zaghloul MMY, Zaghloul MYM, Zaghloul MMY (2017) Experimental and modeling analysis of mechanical-electrical behaviors of polypropylene composites filled with graphite and MWCNT fillers. Polym Testing 63:467-474. https://doi. org/10.1016/j.polymertesting.2017.09.009

[10] Jafari Y, Ghoreishi SM, Shabani Nooshabadi M (2017) Electrosynthesis, characterization and corrosion inhibition study of dbsa-doped polyaniline coating on 310 stainless steel. Iran J Chem Chem Eng 36(5):23-32

[11] Nagashima A et al (1993) Electronic structure of monolayer graphite on some transition metal carbide surfaces. Surf Sci 287-288(PART 2):609-613. https://doi.org/10.1016/0039-6 028(93)91037-P

[12] Nanoelectronics G et al (2007) Berg+04Jpcb. 1-5. https://d oi.org/10.1021/jp040650f.

[13] Wu Z-S et al (2009) Field emission of single-layer graphene films prepared by electrophoretic deposition. Adv Mater 21(17):1756-1760. https://doi.org/10.1002/adma.200802560

[14] Zhu G, Pan L, Lu T, Xu T, Sun Z (2011) Electrophoretic deposition of reduced graphene-carbon nanotubes composite films as counter electrodes of dye-sensitized solar cells.
J Mater Chem 21(38):14869-14875. https://doi.org/10.103 9/c1jm12433a

[15] Eda G, Emrah Unalan H, Rupesinghe N, Amaratunga GAJ, Chhowalla M (2008) Field emission from graphene based composite thin films. Appl Phys Lett 93(23):1-4. https://doi. org/10.1063/1.3028339

[16] Nethravathi C, Rajamathi M (2008) Chemically modified graphene sheets produced by the solvothermal reduction of colloidal dispersions of graphite oxide. Carbon N Y 46(14):1994-1998. https://doi.org/10.1016/j.carbon.2008.08 .013

[17] Zaghloul MYM, Zaghloul MMY, Zaghloul MMY (2021) Developments in polyester composite materials - an indepth review on natural fibres and nano fillers. Compos Struct 278:114698. https://doi.org/10.1016/j.compstruct.202 1.114698

[18] Park JH, Kim JS, Park JM (2013) Electrophoretic deposition of nano-ceramics for the photo-generated cathodic corrosion protection of steel substrates. Surf Coat Technol 236:172-181. https://doi.org/10.1016/j.surfcoat.2013.09.044

[19] Zaghloul MMY, Mohamed YS, El-Gamal H (2018) Fatigue and tensile behaviors of fiber-reinforced thermosetting composites embedded with nanoparticles. J Compos Mater 53(6):709-718. https://doi.org/10.1177/0021998318790093

[20] Mohamed YS, El-Gamal H, Zaghloul MMYM (2018) Microhardness behavior of fiber reinforced thermosetting composites embedded with cellulose nanocrystals. Alexandria Eng J 57(4):4113-4119. https://doi.org/10.1016/j.aej.2 018.10 .012

[21] Zaghloul MMY (2018) Effect of nano particles on the mechanical properties of thermosetting polymeric materials reinforced with glass fibers, M. Sc thesis, Faculty of Engineering, Alexandria University, Egypt

[22] Aly KI, Mahdy A, Hegazy MA, Al-Muaikel NS, Kuo S-W, Gamal Mohamed M (2020) Corrosion resistance of mild steel coated with phthalimide-functionalized polybenzoxazines. Coatings 10:1114. https://doi.org/10.3390/coating s10111114

[23] Mohamed MG, Kuo SW, Mahdy A, Ghayd IM, Aly KI (2020) Bisbenzylidene cyclopentanone and cyclohexanonefunctionalized polybenzoxazine nanocomposites: synthesis, characterization, and use for corrosion protection on mild steel. Mater Today Commun 25:101418. https://doi.org/10. 1016/j.mtcomm.2020.101418

[24] Kiran NU, Dey S, Singh BP, Besra L (2017) Graphene coating on copper by electrophoretic deposition for corrosion prevention. Coatings 7(12):214. https://doi.org/10.3390/coa tings 7120214

[25] Stejskal J (2017) Conducting polymer hydrogels, vol 71. Elsevier, p 2 
[26] Li G, Martinez C, Semancik S (2005) Controlled electrophoretic patterning of polyaniline from a colloidal suspension. J Am Chem Soc 127(13):4903-4909. https://doi. org/10.1021/ja0441763

[27] Gomes EC, Oliveira MAS (2012) Chemical polymerization of aniline in hydrochloric acid $(\mathrm{HCl})$ and formic acid $(\mathrm{HCOOH})$ media. Differences between the two synthesized polyanilines. Am J Polym Sci 2(2):5-13. https://doi.org/10. 5923/j.ajps.20120202.02

[28] Krishnani KK et al (2013) Hexavalent chromium removal mechanism using conducting polymers. J Hazard Mater 252-253:99-106. https://doi.org/10.1016/j.jhazmat.2013.01. 079

[29] Hares E, Hammad AS (2019) Electrophoretic deposition of graphene oxide nanosheets on copper pipe for electrophoretic deposition of graphene oxide nanosheets on copper. Arab J Sci Eng 44(6):5559-5569. https://doi.org/10. 1007/s13369-019-03872-0

[30] Amrollahi P, Krasinski JS, Vaidyanathan R, Tayebi L, Vashaee D (2016) Electrophoretic deposition (EPD): fundamentals and applications from nano- to microscale structures. Handbook of nanoelectrochemistry. Springer International Publishing, Cham, pp 561-591

[31] Boccaccini AR (2004) The use of electrophoretic deposition for the fabrication of ceramic matrix composites. Mater Sci Forum 455:221-224. https://doi.org/10.4028/www.scientific. net/msf.455-456.221

[32] Wu T-M, Lin Y-W, Liao C-S (2004) Preparation and characterization of polyaniline/multi-walled carbon nanotube composites. Corbon 43(4):734-740. https://doi.org/10.1016/ j.carbon.2004.10.043

[33] Hamid ZA, Gomaa MH, Rehim SSA, Hamid MA, Ibrahim A (2019) Synthesis and Characterization of nanostructured polyaniline thin films with superhydrophobic properties. Coatings 9(11):748. https://doi.org/10.3390/ COATINGS9110748

[34] Reka Devi M, Saranya A, Pandiarajan J, Dharmaraja J, Prithivikumaran N, Jeyakumaran N (2019) Fabrication, spectral characterization, XRD and SEM studies on some organic acids doped polyaniline thin films on glass substrate. J King Saud Univ Sci 31(4):1290-1296. https://doi.org/10. 1016/j.jksus.2018.02.008

[35] Chakraborty P, Kothari A, Nagarajan R (2018) Highly ordered polyaniline as an efficient dye remover. Adsorpt Sci Technol 36(1-2):429-440. https://doi.org/10.1177/ 0263617417700146

[36] Elnaggar EM, Kabel KI, Farag AA, Al-Gamal AG (2017) Comparative study on doping of polyaniline with graphene and multi-walled carbon nanotubes. J Nanostructure Chem 7(1):75-83. https://doi.org/10.1007/S40097-017-0217-6
[37] Ali Y, Kumar V, Sonkawade RG, Shirsat MD, Dhaliwal AS (2013) Two-step electrochemical synthesis of Au nanoparticles decorated polyaniline nanofiber. Vacuum 93:79-83. h ttps://doi.org/10.1016/J.VACUUM.2013.01.007

[38] Shaikh AA, Waikar MR, Sonkawade RG (2019) Effect of different concentrations of $\mathrm{KMnO}_{4}$ precursor on supercapacitive properties of $\mathrm{MnO}$ thin films. J Electron Mater 48(12):8116-8128. https://doi.org/10.1007/S11664-019-076 $48-\mathrm{Y}$

[39] Butoi B, Groza A, Dinca P, Balan A, Barna V (2017) Morphological and structural analysis of polyaniline and poly(o-anisidine) layers generated in a dc glow discharge plasma by using an oblique angle electrode deposition configuration. Polymers 9(12):732. https://doi.org/10.3390/ POLYM9120732

[40] Freitas TV, Sousa EA, Fuzari GC, Arlindo PS (2018) Different morphologies of polyaniline nanostructures synthesized by interfacial polymerization. Mater Lett 224:42-45. h ttps://doi.org/10.1016/j.matlet.2018.04.062

[41] Mitra M et al (2015) Reduced graphene oxide-polyaniline composites - Synthesis, characterization and optimization for thermoelectric applications. RSC Adv 5(39):31039-31048. h ttps://doi.org/10.1039/c5ra01794g

[42] Hassanien AS, Akl AA (2019) Effect of Se addition on optical and electrical properties of chalcogenide CdSSe thin films. Superlattices Microstruct 89(January):153-169. http s://doi.org/10.1016/j.spmi.2015.10.044

[43] Liang S, Yi M, Shen Z, Liu L, Zhang X, Ma S (2014) Onestep green synthesis of graphene nanomesh by fluid-based method. RSC Adv 4(31):16127. https://doi.org/10.1039/c4ra $01250 \mathrm{j}$

[44] Chen J, Wang H, Deng J, Xu C, Wang Y (2018) Lowcrystalline tungsten trioxide anode with superior electrochemical performance for flexible solid-state asymmetry supercapacitor. J Mater Chem A 6(19):8986-8991. https://d oi.org/10.1039/C8TA01323C

[45] Sawant SA, Waikar MR, Rasal AS, Chodankar GR (2021) Chemical synthesis and supercapacitive evaluation of polyaniline nanofibers (PANINFs). J Mater Sci Mater Electron 32(9):11865-11876. https://doi.org/10.1007/s10854-02 1-05816-7

[46] Kowalczuk D, Pitucha M (2019) Application of FTIR method for the assessment of immobilization of active substances in the matrix of bio medical materials. Materials 12(18):2972. https://doi.org/10.3390/ma12182972

[47] Ami D, Natalello A, Doglia SM (2012) Fourier transform infrared microspectroscopy of complex biological systems: from intact cells to whole organisms. In: Uversky V, Dunker A (eds) Intrinsically disordered protein analysis. Methods in molecular biology (Methods and protocols), vol 895. 
Humana Press, Totowa, NJ. https://doi.org/10.1007/978-161779-927-3 7

[48] Ramírez-Hernández A, Aguilar-Flores C, Aparicio-Saguilán A (2019) Fingerprint analysis of ftir spectra of polymers containing vinyl acetate. DYNA 86(209):198-205. https://d oi.org/10.15446/DYNA.V86N209.77513

[49] Radhakrishnan S, Rao CRK, Vijayan M (2011) Performance of conducting polyaniline-DBSA and polyaniline-DBSA/ $\mathrm{Fe}_{3} \mathrm{O}_{4}$ composites as electrode materials for aqueous redox supercapacitors. J Appl Polym Sci 122(3):1510-1518. http s://doi.org/10.1002/app.34236

[50] Bian C, Yu Y, Xue G (2007) Synthesis of conducting polyaniline $/ \mathrm{TiO}_{2}$ composite nanofibres by one-step in situ polymerization method. J Appl Polym Sci 104(1):21-26. h ttps://doi.org/10.1002/APP.25636

[51] Babazadeh M, Zalloi F, Olad A (2014) Fabrication of conductive polyaniline nanocomposites based on silica nanoparticles via in-situ chemical oxidative polymerization technique. Synth React Inorg Metal-Org Nano-Met Chem 45(1):86-91. https://doi.org/10.1080/15533174.2013. 818687

[52] Mostafaei A, Zolriasatein A (2012) Synthesis and characterization of conducting polyaniline nanocomposites containing $\mathrm{ZnO}$ nanorods. Prog Nat Sci Mater Int 22(4):273-280. https://doi.org/10.1016/J.PNSC.2012.07.002

[53] Melad O, Alhendawi H, Fayyad M (2014) The Influence of organic solvents on the polymerization of polyaniline. Res Rev J Chem 3(4): 40-47. Available: http:/www.rroij.com/ open-access/the-influence-of-organic-solvents-on-the-polym erization-of-polyaniline-40-47.pdf. (Online)

[54] Direksilp C, Sirivat A (2020) Synthesis and characterization of hollow-sphered poly(N-methyaniline) for enhanced electrical conductivity based on the anionic surfactant templates and doping. Polymers 12(5):1023. https://doi.org/10.3390/ POLYM12051023

[55] Beygisangchin M, Rashid SA, Shafie S, Sadrolhosseini AR, Lim HN (2021) Preparations, properties, and applications of polyaniline and polyaniline thin films - a review. Polymers (Basel) 13(12):2003. https://doi.org/10.3390/polym13122003

[56] Lowry GV et al (2016) Environmental science nano guidance to improve the scientific value of zeta- potential measurements in nanoEHS. Environ Sci Nano 3:953-965. h ttps://doi.org/10.1039/C6EN00136J

[57] Taqvi S, Bassioni G (2015) Understanding wettability through zeta potential measurements. J Chem 1:1-19

[58] Ostolska I (2014) Application of the zeta potential measurements to explanation of colloidal $\mathrm{Cr}_{2} \mathrm{O}_{3}$ stability mechanism in the presence of the ionic polyamino acids. Colloid Polym Sci 292:20-31. https://doi.org/10.1007/s003 96-014-3276-y

[59] Çabuk M (2016) Colloidal behaviors of conducting polymer/chitosan composite particles. In: Rahman M, Asiri A (eds) Advances in colloid science, IntechOpen. https://doi. org/10.5772/65125

[60] Deshpande PP, Jadhav NG, Gelling VJ, Sazou D (2014) Conducting polymers for corrosion protection: a review. J Coat Technol Res 11(4):473-494. https://doi.org/10.1007/ s11998-014-9586-7

[61] He W et al (2013) Electrophoretic deposition of graphene oxide as a corrosion inhibitor for sintered NdFeB. Appl Surf Sci 279:416-423. https://doi.org/10.1016/j.apsusc.2013.04. 130

[62] Al-Amiery AA, Ahmed MHO, Abdullah TA, Gaaz TS, Kadhum AAH (2018) Electrochemical studies of novel corrosion inhibitor for mild steel in $1 \mathrm{M}$ hydrochloric acid. Results Phys 9:978-981. https://doi.org/10.1016/j.rinp.2018. 04.004

[63] Gallegos-Melgar A, Serna SA, Lázaro I, Gutiérrez-Castañeda E-J, Mercado-Lemus VH, Arcos-Gutierrez H, Hernández-Hernández $\mathrm{M}$, Porcayo-Calderón $\mathrm{J}$, Mayen $\mathrm{J}$, Monroy MDA (2020) Potentiodynamic polarization performance of a novel composite coating system of $\mathrm{Al}_{2} \mathrm{O}_{3} /$ chitosan-sodium alginate, applied on an aluminum AA6063 alloy for protection in a chloride ions environment. Coatings 10(1):45. https://doi.org/10.3390/coatings 10010045

[64] Dhanabal T, Amirthaganesan G, Ravichandran J (2011) Pitting corrosion protection of low nickel stainless steel by electropolymerized conducting polymer coating in $0.5 \mathrm{M}$ $\mathrm{NaCl}$ solution. Bull Mater Sci 34(3):563-569. https://doi. org/10.1007/s12034-011-0113-5

[65] Chen F, Liu P (2011) Conducting polyaniline nanoparticles and their dispersion for waterborne corrosion protection coatings. ACS Appl Mater Interfaces 3(7):2694-2702. http s://oi.org/10.1021/AM200488M

[66] Sarkar N, Sahoo G, Das R, Prusty G, Sahu D, Swain SK (2016) Anticorrosion performance of three-dimensional hierarchical PANI@BN nanohybrids. Ind Eng Chem Res 55(11):2921-2931. https://doi.org/10.1021/acs.iecr.5b04887

Publisher's Note Springer Nature remains neutral with regard to jurisdictional claims in published maps and institutional affiliations. 